\title{
Circular Cumulative Causation (CCC) à la Myrdal and Kapp - Political Institutionalism for Minimizing Social Costs
}

Sebastian Berger

\begin{abstract}
This paper reconstructs the CCC from the writings of Myrdal and Kapp to explore the unique characteristics of this key concept of institutional economics. Moreover, the paper demonstrates the CCC's application to minimize social costs and its implications for Political Institutionalism. Incorporating new unpublished material from the Kapp Archive, namely the Myrdal-Kapp correspondence and Kapp's CCC lecture notes, the paper provides insights about the cooperation between the two economists and about Kapp's conceptual understanding of CCC. In addition, important differences to Veblen's $\mathrm{CC}^{\mathrm{V}}$ and Kaldor's $\mathrm{CC}^{\mathrm{K}}$ are pointed out to underline the CCC's uniqueness and its significance for institutional economics.
\end{abstract}

Keywords: Kapp, Myrdal, Circular Cumulative Causation, social costs, political institutionalism

JEL Classification Codes: B15, B25, B5, D63, O13

This paper reconstructs the CCC's original meaning, and methodology from the writings of Myrdal and Kapp to explore the unique characteristics of this key concept of institutional economics. Moreover, the paper demonstrates the CCC's application to minimize social costs via economic planning and its implications for Political Institutionalism, pursuing the research project outlined in the Journal of Economic Issues, (Berger and Forstater 2007). Incorporating new unpublished material from the Kapp Archive, namely the Myrdal-Kapp correspondence and Kapp's CCC lecture notes, the paper provides valuable insights about the cooperation between the two economists, and about Kapp's conceptual understanding of CCC. In the second part of the paper, important differences to Veblen's Cumulative Change $\mathrm{CC}^{\mathrm{V}}$ and Kaldor's Cumulative Causation $\mathrm{CC}^{\mathrm{K}}$ are pointed out to underline the CCC's uniqueness and significance for institutional economics.

The author is a Visiting Lecturer at the University of Missouri - Kansas City. This paper was presented at the annual meeting of the Association for Evolutionary Economics in New Orleans, January 4-6, 2008. 


\section{The Origin of CCC}

Myrdal formulated the CCC for the first time in Appendix 3 of American Dilemma The Negro Problem and Modern Democracy (1944), using it as a research hypothesis for the circular (self-reinforcing) causation between prejudices, institutions, and poverty. This triggers a vicious circle or "cumulative effect" of increasing inequalities, and poverty. Myrdal defined two distinct elements of the CCC, i.e., circular causation and its cumulative effect, in Asian Drama - An Inquiry into the Poverty of Nations (1968):

[. . . circular causation will give rise to a cumulative movement only when [. . .] a change in one of the conditions will ultimately be followed by a feed-back of secondary impulses [. . . big enough not only to sustain the primary change, but to push it further. Mere mutual causation is not enough to create this process. (Myrdal 1968, 1875)

Elsewhere he had formulated:

Because of such circular causation a social process tends to become cumulative and often to gather speed at an accelerating rate. (Myrdal 1957, 13)

Kapp applied CCC throughout his analyses of social costs since the 1940s, and systematically elaborated the concept's significance for the integration of the social sciences in the 1950s (Kapp [1950] [1963] 1977, 23, 25; 1961, 183, 187-8).

\section{Meaning and Methodology}

The CCC is the main antithesis to the mechanistic analogy and stable equilibrium of the social and economic system. As such it denies a necessary ameliorative trend in development, rejects stage theories, and anticipates the danger of poverty, and societal crisis. However, CCC is no doctrine of hopelessness because vicious circles can be broken, virtuous circles are possible, and a cumulative process also calls forth counteracting forces (Myrdal 1944, 1065; 1957, 35; 1968, 1857, 1859; Kapp, unpublished lecture notes).

As a precondition for self-reinforcing causation, CCC presupposes reciprocal causation and rejects the "primum mobile" causation theory (Kapp 1961, 188). Thereby, the CCC takes a stand in an old philosophical debate about cause and effect. For instance, Hegel was convinced that the reciprocal relation of cause and effect is the next truth that science will discover, whereas Schopenhauer stated that an effect cannot be the cause of its cause. Also, Marx saw the development of the whole as being constituted of factors that interact with each other and with the whole. Regarding Marxian dialectics, Kapp argued that the CCC neither doubts the relevance of ideological nor material factors but that it rejects that one factor is per se 
exclusive and that the analysis can be restricted to it. Contradictions between material conditions and ideas, etc., are however, possible (Kapp, unpublished lecture notes, Kapp Archive). Myrdal rejected Marxian dialectics if they are interpreted as attributing causal potency to the economic factor alone (Myrdal 1968, 1855-1905).

If social events and social change emerge in a process of reciprocal interaction between the elements of the system (i.e., within the inner structure), it is no longer adequate to attribute causal potency to an individual variable or impulse. Rather, the outcome (the event, the process) must be viewed as the result of the entire initial situation and the interaction process as well the basic properties of the total social structure. (Kapp 1961, 188)

Therefore, attributing causal potency to the economic factor leads to only seemingly clear correlations. The CCC hence focuses on all relevant factors and rejects working with analytically closed models. The relevant factors can, of course, only be determined empirically in a given situation. Denying the existence of a primary cause neither implies a denial of the causal principle nor renders the search for relevant factors, their interdependence, or the direction of their change futile. The economic process is part of a larger social process and has to be analyzed as such. Thus the CCC, as applied in the context of economic planning, has focused on the conditions of the following categories of the social system that are by no means exclusive: (1) output and incomes; (2) conditions of production; (3) levels of living; (4) attitudes toward life and work; (5) policies; and (6) institutions (Myrdal 1968). The CCC analysis confirmed the Veblenian account of the role of institutions (Kapp 1961; 1963b):

[. . .] certainly the main resistance to change in the social system stems from attitudes and institutions. They are part of the inherited culture and are not easily or rapidly moved in either direction. Even in the very long run, attitudes and community institutions may stay much the same [. . .] the inertia of attitudes and institutions may be formidable [...] [and] the main reason why a 'take off' may easily be abortive [. . .]. (Myrdal 1968, 1872)

Kapp even applied the CCC to circular causation between the open economic system and the environment, as well as circular causation in the environment, e.g., synergetic effects of different pollutants that disrupt the human environment in a cumulative process. This approach is similar to systems thinking. ${ }^{1}$ In light of the social system dynamics, exhibiting non-constant reciprocal interactions between the system and its parts that are often characterized by an uneven spread along the time axis, Kapp followed that the power of scientific analysis is limited and that it is doubtful whether a general theory or law can be expected of social science. Consequently, Kapp as well as Myrdal asserted that there exists no math of social 
change, and rejected formal modeling (Kapp unpublished lecture notes; 1961, 188; 1965a; Myrdal 1968, 1866).

Kapp considered the CCC to be the key concept of institutional economics (Kapp 1977; 1968), and writes to Myrdal:

I read the Appendix [galley proofs of Appendix 2 of Asian Drama] with great profit; I am very much impressed [. . .] I think we now have a synthesis of an analysis in the sense of a theoretical framework and a system of tools for the study of the underdeveloped world. [ . . .] your tools go much beyond the underdeveloped countries and [. . .] a good deal of your new framework of analysis could be fruitfully applied in the study of developed countries. (Kapp, Oct. 19, 1967. Unpublished Kapp-Myrdal Correspondence.)

Taking CCC with its emphasis on interrelatedness seriously demands interdisciplinarity, and questions the autonomy of each social science (Kapp unpublished lecture notes; 1961). Moreover, Kapp considered the CCC to have the characteristics of a scientific "paradigm" with its own analytical apparatus, philosophical perspective, and hypothesis. He lists its main characteristics as follows: CCC (1) frames problems, (2) brings problems closer to solution, (3) necessitates an identification of relevant causal factors, (4) necessitates a causal analysis of real interaction relationships, (5) necessitates systems view, (6) necessitates analysis of temporal processes, and (7) avoids teleology, the projection of ready-made meanings, relationships, results, and processes. To prevent the turning of CCC into a dogma, Kapp even proposed to explore if there is indeed no single determining factor (Kapp, unpublished lecture notes).

\section{Minimizing Social Costs via Economic Planning}

Applying the CCC to economic planning, Myrdal and Kapp both started from explicit value premises (Myrdal 1929; 1944, 1035-1064; 1958; Kapp 1950; 1965a; 1973a). Desirable and possible positions of the system have to be justified normatively because they are neither automatic, nor natural (Kapp, unpublished lecture notes). Both regarded it as a threat to science, when research results are deemed "objective" while they are determined by hidden pre-analytical values.

The values made explicit by Myrdal are the democratic equality ideals of the enlightenment that played a major role in the radical reforms of feudalism and the implementation of democratic institutions in Europe and the United States. This led to Myrdal's concern for poverty and increasing disparities between the rich and the poor that is similar to Kapp's concern for the fulfillment of basic human needs, i.e. his social minima approach (Kapp 1965a; 1965b):

I have long felt that we are kindred souls and I am quoting you in a big book on South Asia [. . .] [I want to] thank you for your most interesting and inspiring article, Social Economics and Social Welfare Minima [...]. (Myrdal Dec. 5, 1966) 
Reflecting these value dispositions, the CCC serves as a conceptual tool ${ }^{2}$ to break the vicious circle of poverty (Myrdal 1970; Kapp 1973a) that is caused by inequalities in the (a) economic (e.g., income inequalities, including the unequal distribution of land); (b) social (e.g., lack of social mobility, including unequal educational opportunities); and (c) political (e.g., unequal participation in the political process, including qualitatively defective administration) realms within poor countries as well as their unequal trade relations with industrialized countries. In self-reinforcing circular causation these inequalities further inequalities most in poor regions. In other words, these inequalities are the cause and effect of poverty (Kapp 1973a; Myrdal 1970). ${ }^{3}$ Poverty as a form of insufficient satisfaction of basic human needs is a substantive indicator of social costs (Kapp 1963a).

Complementing the cause-effect analysis with a normative means-ends dimension, Kapp and Myrdal proposed "political" economics that is concerned with economic planning in real terms to guarantee social minima, and minimize social costs (Myrdal 1960; 1968, 1879; Kapp 1965b; 1973b; Berger and Forstater 2007). Economic planning with monetary indicators usually leads to a selection of growth and maximization of profits at the expense of environmental goals. Social costs of environmental disruption jeopardize the fulfillment of basic human needs because they mostly affect the weakest that are usually more exposed or have less means to protect themselves. This is an instance of circular cumulative causation of social costs. In contrast, economic planning that aims at guaranteeing social minima, according to Kapp, needs a comprehensive system of social accounting with a diversity of heterogeneous indicators. Such indicators reflect the present state and exigencies of the socio-ecological system and its effect on the condition of human life with respect to explicit socio-ecological objectives (minimum socio-ecological standards). Due to CCC, the indicators are interrelated and the deterioration of the quality in one socio-ecological category influences other categories. The indicators, furthermore, have to reveal the actual and potential dangers for human health and well-being, and for social reproduction. Growth is understood as an improvement in the socioecological conditions, measured in real terms via socio-ecological indicators in terms of which development planning takes place (Myrdal 1970; Kapp 1973a, 4). Consequently, growth and the improvement in the quality of the social and ecological environment are identical goals, and there is no trade-off in this integrative view of "eco-development" (Kapp [1976b] 1977). Kapp cautioned, however, that it is important not to conceal that vested interests are affected by implementing a comprehensive accounting system (Kapp 1973b).

CCC leads to alternative criteria for economic planning. The environment's "revolutionary" character is that environmental values are social use values. Kapp argued that environmental policies, the evaluation of environmental goals and the establishment of priorities require substantive economic indicators in terms of social use values (politically evaluated) for which the formal calculus in monetary exchange values fails to provide a real measure. In this context, Kapp referred to Max Weber's discussion of Otto v. Neurath's "Naturalrechnung" (accounting in material units) who had "taken up the hint" of Marx and Engels that not exchange value but use value, 
i.e., "useful effects" and free "disposable time" are the source of real wealth and thus quality of life. Hence, the criteria for planning are the useful effects of different goods and services balanced against the required expenditure of labor (Kapp [1973b] 1974).

\section{Differences to Veblen's and Kaldor's CC}

Building on previous research (Berger and Elsner 2007), this paper furthermore argues that Veblen's concept of "cumulative change" $\left(\mathrm{CC}^{\mathrm{V}}\right)$ differs from Myrdal's CCC. Applying it mainly to "the sequence of change in the methods of dealing with the material means of life" (Veblen 1898, 387), Veblen described the economic life history as a "cumulative process of adaptation of means to ends that cumulatively change as the process goes on [. . ." (Veblen 1898, 391). The main characteristic of an evolutionary economist is that "he insists on an answer in terms of cause and effect [. . .] the notion of cumulative causation" (Veblen 1898, 377). Thus his concept, per se, does not contain the idea of a self-reinforcing (positive) feedback and even states that there is "no trend" in cumulative causation (Veblen 1907, 304) whereas CCC explicitly refers to trends, such as increasing inequality and poverty. However, similarities exist and have been noticed by Kapp: (a) the rejection of a tendency toward equilibrium, and (b) viewing cultural and economic processes as unending, non-teleological, and moved by institutional inertia (Kapp [1950] [1963] 1977, 25).

Kaldor's principle of "cumulative causation" (CCK) differs substantially from the CCC in the Myrdal-Kapp tradition in terms of method, research interest, and application, which confirms Setterfield's finding of a unique Kaldorian tradition (Setterfield 2001, 109). Kaldor's interpretation of CCC is mainly based on Myrdal's Economic Theory and Under-Developed Regions (1957), leaving the more important later applications aside. Hence, it remains unclear how much of the CCC he agreed with. This is not to deny certain similarities (e.g., the rejection of equilibrium economics, unequal trade). The question is whether these similarities are substantial and whether they outweigh important differences.

In a subchapter called "the principle of cumulative causation" Kaldor wrote "what Myrdal called the principle of 'circular and cumulative causation' [. . .] is nothing else but the existence of increasing returns to scale [. . .]" (Kaldor [1970] 1978, 143). In another subchapter called "the theorem of endogenous and cumulative change," Kaldor asserted that "with increasing returns change becomes progressive and propagates itself in a cumulative way. Myrdal [. . .] called this the "principle of circular and cumulative causation"” (Kaldor [1972] 1978, 186).

It seems that because Kaldor was mostly interested in the economic mechanism of "increasing returns" he interprets Myrdal accordingly. This is, however, a much more narrow approach than the one taken by CCC à la Myrdal-Kapp. It is true that Kaldor generally conceded the importance of non-economic factors in the development process, such as the effects of governmental intervention and training on growth (Argyrous 2001, 105; Toner 2001, 99). Unlike Myrdal and Kapp, however, in Kaldor's writings on $\mathrm{CC}^{\mathrm{K}}$ an attempt to explain how these relevant factors of the 
social system are interrelated is missing. Although Kaldor's "interrelatedness" portrayed the economy as a "complex web of interrelations" (Argyrous 2001, 105) it focused mainly on the interdependencies of "economic" components, such as machinery, and organizational structure (Toner 2001, 100). The fact that Kaldor's analysis of institutions was marginal and of secondary importance has also been noticed by Toner $(1999,115)$. On the whole it seems that Kaldor's research interest is more limited to the "economic," which may explain why he preferred the term "cumulative" over "circular causation."

Unlike Myrdal and Kapp, Kaldor did not state his value premises and did not apply $\mathrm{CC}^{\mathrm{K}}$ for political economics. His $\mathrm{CC}^{\mathrm{K}}$ considered unequal development even as the outcome of a "natural cause of events" (Kaldor [1970] 1978, 148) due to "deepseated causes that are unlikely to be rendered inoperative" (Kaldor [1970] 1978, 144). This methodology seems very different from CCC, which was concerned with poverty and considered inequality as something that could be changed via policy. Another divergence is that Kaldor takes industrial growth and monetary indicators as a given. Myrdal and Kapp critiqued this "mainstream" approach because industrial development has little meaning when poverty of a large part of the population prevails and when it is accompanied by environmental disruption that contributes to the vicious circle of poverty. Moreover, indexes of exchange values are, according to Kapp, arbitrary because they take asymmetries in purchasing power for granted and abstract from many relevant conditions so that they cannot adequately reflect the status quo of the quality of life.

\section{Conclusion}

This paper shows how Kapp and Myrdal developed the CCC into the key concept of institutional economics and demonstrates how both made it a cornerstone for Political Institutionalism by applying it to economic planning to effectively minimize social costs. In addition, this paper points out the differences to Veblen's $\mathrm{CC}^{\mathrm{V}}$ and Kaldor's $\mathrm{CC}^{\mathrm{K}}$, validating that the $\mathrm{CCC}$ holds the fullest theoretical and conceptual potential for institutional economics.

\section{Notes}

1. The emphasis CCC places on interrelatedness is closely related to conceptual developments in the social sciences (e.g., systems theory, system dynamics, cybernetics, complexity theory): Myrdal and Kapp considered the economic system to be an open system in reciprocal interaction with the surrounding systems (Myrdal 1976, 215; Kapp 1976a) implying the possibility of disruptive effects that are potentially threatening to human survival (Kapp 1976a; Berger and Elsner 2007).

2. Kapp also used the concept of "social reproduction" developed by the Physiocrats and later adopted by Marx and Engels, which he considered a tool for the elaboration of useful hypotheses regarding defects and inefficiencies of a social system (Kapp [1973b] 1974, 132, 134-5).

3. The CCC exhibits similarities to the development theories of F. Perroux ("domination effect") and J. Galtung ("center-periphery"). The CCC, according to Kapp, however, seems to be more generally applicable. 


\section{References}

Argyrous, George. "Setterfield on Cumulative Causation and Interrelatedness: A Comment." Cambridge Journal of Economics 25, 1 (2001): 103-106.

Berger, Sebastian and Wolfram Elsner. "European Contributions to Evolutionary Institutional Economics:

The Cases of Cumulative Circular Causation (CCC) and Open System Approach (OSA). Some Methodological and Policy Implications." Journal of Economic Issues 41, 2 (2007): 529-537.

Berger, Sebastian and Matthew Forstater. "Towards Political Institutionalist Economics. Kapp's Social Costs, Lowe's Instrumental Analysis, and the European Institutionalist Approach to Environmental Policy." Journal of Economic Issues 41, 2 (2007): 539-546.

Kaldor, Nicholas. The Case of Regional Policies, in: Further Essays in Economics. London: Holmes and Meier Publishers [1970] 1978.

-The Irrelevance of Equilibrium Economics, in: Further Essays in Economics. London: Holmes and Meier Publishers [1972] 1978.

Kapp, K. W. The Social Costs of Business Enterprise (2nd revised and enlarged edition of Social Costs of Private Enterprise (1950)). Nottingham: Spokesman University Paperback, [1963] 1977.

—. Towards a Science of Man in Society. A Positive Approach to the Integration of Social Knowledge. The Hague: Martinus Nijhoff, 1961.

—. "Social Costs and Social Benefits - A Contribution to Normative Economics." In Probleme der normativen Ökonomik und der wirtschaftspolitischen Beratung, edited by E. v. Beckerath and H. Giersch, 183-210. Verein für Sozialpolitik. Berlin: Duncker \& Humblot, 1963a.

—. Hindu Culture, Economic Development and Economic Planning in India. Bombay/London: Asia Publishing House, 1963 b.

—_. "Economic Development in a New Perspective: Existential Minima and Substantive Rationality." Kyklos 17, 1 (1965a): 49-79.

—. "Social Economics and Social Welfare Minima." In Towards a Sociology of Culture in India, Essays in Honor of Dr. D. P. Mukerji, edited by T.K.N. Unnithan et al., pp 1-12. New Delhi: Prentice Hall of India, 1965b.

—. "In Defence of Institutional Economics." Swedish Journal of Economics 70, 1 (1968): 1-18.

—_. "Entwicklungspolitik in neuer Perspektive: Bemerkungen zu Gunnar Myrdals ,Politisches Manifest über die Armut in der Welt'." Blätter für deutsche und internationale Politik 18, 3 (1973a): 1-12.

_. "Environmental Indicators as Indicators of Social Use Value." In Environmental Policies and Development Planning in Contemporary China and other Essays, pp. 127-138. Paris/The Hague: Mouton, [1973b] 1974.

—. "The Open-System Character of the Economy and its Implications." In Economics in the Future, edited by Kurt Dopfer, pp.90-105. London: The Macmillan Press Ltd., 1976a.

—. "Development and Environment: Towards a New Approach to Socio-economic and Environmental Development." In Economics in Institutional Perspective - Memorial Essays in Honor of K. W. Kapp edited by Rolf Steppacher, et al., pp. 205-218. Lexington, MA, Toronto: Lexington Books, [1976b] 1977.

_. "The Nature and Significance of Institutional Economics." Kyklos 29, 2 (1977): 209-232.

_. Unpublished lecture notes on the CCC; Myrdal-Kapp Correspondence, Kapp Archive, Basle, Switzerland.

Myrdal, Gunnar. Das politische Element in der national-ökonomischen Doktrinbildung, Bonn-Bad Godesberg: Verlag Neue Gesellschaft, [1929] [1932] 1976.

- - American Dilemma:- The Negro Problem and Modern Democracy. New York/London: Harper \& Row, 1944.

—. Economic Theory and Under-Developed Regions. London: Gerald Duckworth, 1957.

- Value in Social Theory - A Selection of Essays on Methodology by Gunnar Myrdal. London: Routledge \& K. Paul, 1958.

—. Beyond the Welfare State - Economic Planning in the Welfare States and its International Implications. New Haven: Yale University Press, 1960.

—. Asian Drama - An Inquiry Into the Poverty of Nations, Vol. III. New York: Pantheon, 1968. 
—. The Challenge of World Poverty, A World Anti-Poverty Program in Outline. New York: Pantheon Books, 1970.

__. "Remarks upon Receipt of the Veblen-Commons Award." Journal of Economic Issues 10, 2 (1970): 215 216.

Setterfield, Mark. 2001. "Cumulative Causation, Interrelatedness and the Theory of Economic Growth: A Reply to Argyrous and Toner." Cambridge Journal of Economics 25 (2001): 97-102.

Toner, Philip. Main Currents in Cumulative Causation - The Dynamics of Growth and Development. New York: St. Martin's Press, 1999.

—_. "'History versus Equilibrium' and the Theory of Economic Growth, by Mark Setterfield: A Comment." Cambridge Journal of Economics 25 (2001): 97-102.

Veblen, Thorstein B. "Why is Economics not an Evolutionary Science?" The Quarterly Journal of Economics 12, 4 (1898): 373-97.

—. "The Socialist Economics of Karl Marx and His Followers." The Quarterly Journal of Economics 21, 2 (1907): 299-322. 
